\title{
Teste de lixiviação de potássio para a avaliação do vigor de sementes de arroz ${ }^{1}$
}

\author{
Ana Paula Piccinin Barbieri²*, Nilson Lemos de Menezes², \\ Gerusa Massuquini Conceiçãoº ${ }^{2}$ Lilian Madruga de Tunes $^{2}$
}

\begin{abstract}
RESUMO - O presente trabalho foi realizado com o objetivo de determinar as condições do teste de lixiviação de potássio para a avaliação do vigor de sementes de arroz. Cinco lotes de sementes da cultivar IRGA 424 e cinco da cultivar Puitá Inta CL foram submetidos a esse teste, cuja eficiência foi comparada à dos testes de germinação, primeira contagem de germinação, frio sem solo, condutividade elétrica massal e emergência de plântulas em campo. A quantidade de potássio exsudada foi determinada em fotômetro de chama, após 30, 60, 90, 120, 150 e 180 minutos de imersão de 50 sementes, em água destilada e deionizada nos volumes de 20 e $50 \mathrm{~mL}$ a $25{ }^{\circ} \mathrm{C}$. O teste de lixiviação de potássio é eficiente para avaliar o vigor de sementes de arroz. A combinação de 50 sementes puras imersas em $50 \mathrm{~mL}$ de água destilada e deionizada, a $25^{\circ} \mathrm{C}$ durante 60 minutos representa o procedimento mais eficiente para classificar lotes de sementes de arroz, em função de sua qualidade fisiológica.
\end{abstract}

Termos para indexação: Oryza sativa L., análise de sementes, qualidade de sementes, teste de vigor.

\section{Evaluation of rice seed vigour by potassium leaching test}

\begin{abstract}
The aim of this study was to determine the conditions of the potassium leaching test for evaluating rice seed vigor. Five seed lots of the IRGA 424 variety and five seed lots of the Puita Inta CL variety were tested, and results compared with those from germination tests, first germination count, cold test (without soil), electrical conductivity and seedling germination in the field. The amount of potassium leachate was determined using a flame photometer, after 30, 60, 90, 120, 150 and 180 minutes of immersing 50 seeds in distilled and deionised water at volumes of 20 and $50 \mathrm{~mL}$ at $25^{\circ} \mathrm{C}$. The combination of 50 pure seeds submerged in $50 \mathrm{~mL}$ of distilled and deionized water at $25{ }^{\circ} \mathrm{C}$ for 60 minutes was the most efficient procedure for classifying the physiological quality of rice seed lots.
\end{abstract}

Index terms: Oryza sativa L., seed quality, seed testing, vigor testing.

\section{Introdução}

A avaliação do vigor de sementes é de fundamental importância para o controle da qualidade, em um programa de produção de sementes. $\mathrm{Na}$ atualidade, uma das principais exigências em termos de avaliação da qualidade das sementes, refere-se à rapidez na obtenção de resultados confiáveis permitindo a agilidade da tomadas de decisões, principalmente no que se refere às operações de colheita, processamento, armazenamento e comercialização, o que diminui riscos e custos.

Testes rápidos de vigor são associados com a determinação das atividades enzimáticas e respiratórias e

${ }^{1}$ Submetido em 26/01/2011. Aceito para publicação em 23/05/2011.

${ }^{2}$ Departamento de Fitotecnia, UFSM, 97105-900 - Santa Maria, RS, Brasil.

*Autor para correspondência <apaulabarbieri@yahoo.com.br> 
com a integridade da membrana celular, como os testes de condutividade elétrica e lixiviação de íons (AbdulBaki e Baker, 1973). O teste de lixiviação de potássio baseia-se em princípio semelhante ao doteste de condutividade elétrica, porém visa à determinação da quantidade de íons de potássio liberada pelas sementes durante a imersão (Dias e Marcos-Filho, 1995).

Durante o processo de imersão das sementes, ocorre a lixiviação de solutos citoplasmáticos no meio líquido de maneira proporcional ao estado de desorganização das membranas e inversamente proporcional à velocidade das membranas se reorganizarem (Vieira, 1994). Dentre os lixiviados liberados na solução de imersão estão açúcares, aminoácidos, ácidos graxos, enzimas e íons orgânicos $\left(\mathrm{K}^{+}, \mathrm{Ca}^{+++}, \mathrm{Mg}^{+++} \mathrm{e} \mathrm{Na}^{+}\right)$.

A elevada lixiviação de solutos das sementes é a primeira consequência da redução do vigor das sementes de um lote, causada pela deterioração e por danos de embebição, os quais interagem entre si, pois sementes mais deterioradas são mais susceptíveis aos danos de embebição e, consequentemente, ao aumento de lixiviados na água de imersão (Matthews e Powell, 2006).

Muitos íons diferentes permeiam simultaneamente as membranas de células vivas, mas o íon potássio tem a concentração mais elevada e a maior permeabilidade em células vegetais (Taiz e Zeiger, 2009). Este íon desempenha papel importante na regulação do potencial osmótico das células vegetais, além de ativar enzimas envolvidas na respiração, na fotossíntese e manter a eletroneutralidade celular.

Ao estudarem sementes de milho, Alves et al. (2004) encontraram, na solução de imersão, maior quantidade de potássio lixiviado do que outros elementos. Tal constatação, igualmente, foi feita em soja por (Dias et al., 1997; Vieira et al., 2008; Fessel et al., 2010).

A lixiviação de potássio tem sido utilizada para avaliar o potencial fisiológico de sementes de diferentes espécies. Em algodão, a avaliação da quantidade de $\mathrm{K}^{+}$liberado pelas sementes embebidas mostrou-se um indicador de qualidade fisiológica mais eficiente do que a quantidade de eletrólitos totais (Woodstock et al., 1985). Em milho, o teste de lixiviação de potássio é uma eficiente alternativa para avaliar o vigor das sementes, proporcionando informações rápidas e consistentes (Miguel e Marcos-Filho, 2002). Da mesma forma, a utilização de 50 sementes em $50 \mathrm{~mL}$ de água, por 2 horas, a $30{ }^{\circ} \mathrm{C}$ foi a combinação mais adequada na separação de lotes de rúcula com relação ao potencial fisiológico (Alves e Sá, 2010). Em sementes de amendoim, a quantidade de potássio lixiviado permitiu a identificação de lotes com diferentes níveis de vigor (Vanzolini e Nakagawa, 2003, Kikuti et al., 2008).

A determinação do potássio lixiviado durante a imersão das sementes tem se mostrado como uma alternativa promissora para a obtenção de informações rápidas sobre a qualidade fisiológica das sementes. Sendo assim, o aperfeiçoamento da metodologia de lixiviação de potássio para a avaliação do potencial fisiológico de sementes de arroz deve ser priorizado, devido à importância econômica dessa espécie, bem como, a grande necessidade de testes rápidos, reproduzíveis e de fácil execução para um programa de controle da qualidade de sementes.

O presente trabalho foi realizado com o objetivo de determinar as condições para o teste de lixiviação de potássio na avaliação da qualidade fisiológica de sementes de arroz.

\section{Material e Métodos}

A pesquisa foi conduzida no Laboratório Didático e de Pesquisas em Sementes (LPDS), do Departamento de Fitotecnia, na Universidade Federal de Santa Maria (UFSM), Santa Maria - RS. Foram utilizados dez lotes de sementes de arroz (Oryza sativa L.), sendo cinco da cultivar Puitá Inta CL e cinco da cultivar IRGA 424, produzidas na safra 2008/2009, nos quais, primeiramente foi feita a caracterização por meio das seguintes determinações e testes:

Teor de água: determinado pelo método de estufa a $105{ }^{\circ} \mathrm{C} \pm 3{ }^{\circ} \mathrm{C}$ por 24 horas com circulação forçada de ar, utilizando-se duas repetições para cada lote, conforme as Regras para Análise de Sementes - RAS (Brasil, 2009).

Teste de germinação: foram utilizadas quatro repetições de 100 sementes para cada lote, semeadas em rolos de papel umedecidos a 2,5 vezes a massa do papel seco e mantidos em germinador regulado a $25{ }^{\circ} \mathrm{C}$. As avaliações foram realizadas aos cinco e aos 14 dias, após início do teste, conforme as RAS (Brasil, 2009), sendo os resultados expressos em porcentagem de plântulas normais.

Primeira contagem do teste de germinação: foi realizada conjuntamente com o teste de germinação, computando-se as porcentagens médias de plântulas normais, após cinco dias da instalação do teste. Os resultados foram expressos em porcentagem de plântulas normais. 
Frio sem solo: foram utilizadas quatro repetições de 100 sementes, distribuídas em rolo de papel toalha, previamente umedecido com água destilada, na razão de 2,5 vezes a massa do papel seco e submetido à temperatura constante de $10{ }^{\circ} \mathrm{C}$, por um período de cinco dias, conforme metodologia proposta pelo Comitê de Vigor, da International Seed Testing Association (ISTA, 1995). Após este período, os rolos foram transferidos para um germinador à temperatura de $25^{\circ} \mathrm{C}$, durante sete dias. Os resultados foram expressos em porcentagem de plântulas normais.

Emergência das plântulas em campo: foi conduzido com quatro repetições de 100 sementes em linhas de 2,0 $\mathrm{m}$ de comprimento com espaçamento de $0,20 \mathrm{~m}$, em que a semeadura foi feita a uma profundidade média de 0,03 m. A avaliação da porcentagem de emergência das plântulas foi efetuada aos sete dias após a semeadura.

Condutividade elétrica massal: conduzido com quatro repetições de 50 sementes para cada lote, para as quais foram determinadas a massa em balança com precisão de $0,001 \mathrm{~g}$, colocadas em copos plásticos com $75 \mathrm{~mL}$ de água destilada e deionizada, mantidos em um germinador a $25{ }^{\circ} \mathrm{C}$. Após $24 \mathrm{~h}$, a condutividade elétrica da solução de imersão foi determinada em condutívimetro marca Digimed, modelo CD-21. Os resultados foram expressos em $\mu \mathrm{S} \mathrm{cm}^{-1} \mathrm{~g}^{-1}$ de sementes.

Lixiviação de potássio: foram estudados os efeitos do período de imersão $(30,60,90,120,150$ e 180 minutos $)$ e do volume de água $(20$ e $50 \mathrm{~mL})$. Foram utilizadas quatro subamostras de 50 sementes fisicamente puras para cada lote. Inicialmente, determinou-se a massa das sementes em balança de precisão de $0,001 \mathrm{~g}$, em seguida as sementes foram colocadas imersas em copos plásticos contendo água destilada e deionizada, sendo estes mantidos em germinador, a temperatura de $25^{\circ} \mathrm{C}$, durante cada período de imersão. Transcorrido o período de imersão, a solução contendo as sementes foi colocada em frascos de vidro, identificados e encaminhados para a determinação de íons. A determinação de potássio foi feita empregando-se o método de fotometria de chama. Os valores foram expressos em $\mu \mathrm{g}$ do íon potássio $\mathrm{g}^{-1}$ de semente, ou seja, ppm de potássio.

Após a obtenção da melhor combinação entre número de sementes e período de imersão para a realização do teste de lixiviação de potássio, esta combinação foi avaliada pela sua aplicação em um grupo de lotes de sementes, com o procedimento descrito a seguir:

Dez lotes de sementes de arroz de diferentes cultivares foram submetidos aos testes de germinação, primeira contagem de germinação e emergência de plântulas conforme descrito anteriormente. Para o teste de lixiviação de potássio foram utilizados quatro repetições de 50 sementes que foram imersas em $50 \mathrm{~mL}$ de água destilada e a leitura realizada após 60 minutos de imersão das sementes.

Análise estatística: foi adotado o delineamento experimental inteiramente casualizado e as análises de variância foram efetuadas no esquema fatorial $5 \times 6 \times 2$ (lotes x períodos de imersão x volume de água), com quatro repetições por tratamento. A fim de atender as pressuposições da análise de variância, os resultados expressos em porcentagem foram transformados em arcsen raiz de $\mathrm{x} / 100$, em que $\mathrm{x}$ representa a porcentagem de plântulas normais obtidas pelos testes. As médias obtidas foram comparadas pelo teste de Scott-Knott, no nível de $5 \%$ de probabilidade de erro, utilizando o programa de análise estatística Sisvar (Ferreira, 2008). Também foram calculados os coeficientes de correlação para todas as combinações entre os testes de lixiviação de potássio e os demais testes. Os dados da etapa final de comprovações da utilidade do teste de lixiviação de potássio foram avaliados com a análise de variância e comparados pelo teste de Scott-Knott, no nível de 5\% de probabilidade de erro.

\section{Resultados e Discussão}

O teor de água das sementes, determinado no momento da caracterização inicial, para a cultivar IRGA 424, variou de $10,2 \%$ a $11,7 \%$ entre os lotes de sementes e, para a cultivar Puitá Inta CL, variou de 10\% a 11,5\% (Tabela 1). Portanto, a pequena variação no teor de água das sementes entre os lotes parece não ser a causa das diferenças observadas nos testes posteriores, como também foi observado por Marcos -Filho (1999), quando a variação situou-se nestes níveis.

Para a cultivar IRGA 424, os dados do teste de germinação (Tabela 1) mostraram que as sementes dos lotes 3,4 e 5 obtiveram maior porcentagem de plântulas normais do que os lotes 1 e 2 . A germinação não definiu completamente a ordem dos lotes quanto a sua qualidade. Pode-se observar que nos testes de emergência de plântulas e de condutividade elétrica, o lote 4 , juntamente com o 1 e 2, foi discriminado como um dos de pior nível de vigor, o que não foi observado no teste de germinação. A germinação é rápida e máxima em condições ótimas de ambiente e, portanto, não prevê o comportamento da semente sob ampla variação das condições (Marcos-Filho, 2005). Isso indica a necessidade da complementação dessas informações através de outros testes. 
Tabela 1. Valores médios da determinação do teor de água (U), teste de germinação $(\mathrm{G})$, primeira contagem de germinação (PC), frio sem solo (TF), emergência em campo (EM) e condutividade elétrica massal (CEM), dos lotes das duas cultivares.

\begin{tabular}{|c|c|c|c|c|c|c|c|}
\hline Tratamento & Lote & $\mathrm{U}(\%)$ & G (\%) & PC (\%) & $\mathrm{TF}(\%)$ & EM (\%) & $\operatorname{CEM}\left(\mu \mathrm{S} . \mathrm{cm}^{-1} \cdot \mathrm{g}^{-1}\right)$ \\
\hline \multirow{5}{*}{ Irga 424} & 1 & 10,2 & $75 \mathrm{~b}$ & $61 \mathrm{~b}$ & $50 \mathrm{c}$ & $68 \mathrm{~b}$ & $31,73 \mathrm{~b}$ \\
\hline & 2 & 11,7 & $84 \mathrm{~b}$ & $78 \mathrm{a}$ & $64 \mathrm{~b}$ & $68 \mathrm{~b}$ & $35,83 \mathrm{~b}$ \\
\hline & 3 & 11,0 & $94 \mathrm{a}$ & $91 \mathrm{a}$ & $84 \mathrm{a}$ & $76 \mathrm{a}$ & 19,46 a \\
\hline & 4 & 11,4 & $88 \mathrm{a}$ & $84 \mathrm{a}$ & $81 \mathrm{a}$ & $70 \mathrm{~b}$ & $32,60 \mathrm{~b}$ \\
\hline & 5 & 10,2 & $94 \mathrm{a}$ & $90 \mathrm{a}$ & $86 \mathrm{a}$ & $73 \mathrm{a}$ & 17,69 a \\
\hline \multirow[t]{2}{*}{ CV $(\%)$} & & & 7,76 & 9,98 & 4,94 & 3,9 & 6,02 \\
\hline & 1 & 10,0 & $96 \mathrm{a}$ & $94 \mathrm{a}$ & $92 \mathrm{a}$ & $79 \mathrm{a}$ & $24,40 \mathrm{a}$ \\
\hline Puitá & 2 & 11,3 & $90 \mathrm{~b}$ & $89 \mathrm{a}$ & $93 \mathrm{a}$ & $81 \mathrm{a}$ & $30,44 \mathrm{~b}$ \\
\hline \multirow[t]{3}{*}{ Inta $C L$} & 3 & 10,9 & $88 \mathrm{~b}$ & $75 \mathrm{~b}$ & $74 \mathrm{c}$ & $69 \mathrm{~b}$ & $26,73 \mathrm{a}$ \\
\hline & 4 & 10,0 & $78 \mathrm{c}$ & $71 \mathrm{~b}$ & $79 \mathrm{~b}$ & $68 \mathrm{~b}$ & $2792 \mathrm{~b}$ \\
\hline & 5 & 11,5 & $87 \mathrm{~b}$ & $78 \mathrm{~b}$ & $79 \mathrm{~b}$ & $73 \mathrm{~b}$ & $26,01 \mathrm{a}$ \\
\hline CV (\%) & & & 5,25 & 8,25 & 3,09 & 5,53 & 6,79 \\
\hline
\end{tabular}

* Médias seguidas pela mesma letra na coluna não diferem entre si, pelo teste de Scott-Knott, (p>0,05).

Na primeira contagem da germinação e no teste de frio apenas o lote 1 foi classificado como de qualidade inferior (Tabela 1), podendo-se deduzir que o lote 1 encontrava-se em estado de deterioração mais avançado do que os demais lotes. As diferenças observadas entre os resultados expressos pelos lotes nestes testes, que não haviam sido detectadas no teste de germinação, podem ser atribuídas ao potencial fisiológico dos lotes testado em situação diferente da ideal.

Os dados de germinação da cultivar Puitá Inta CL classificaram os lotes em três níveis, sendo que o lote 1 obteve maior porcentagem de plântulas normais, o lote 4 menor germinação e os lotes 2,3 e 5 obtiveram porcentagens intermediárias (Tabela 1). Com relação aos testes de vigor, primeira contagem do teste de germinação, frio e emergência de plântulas em campo, os mesmos apresentaram resultados semelhantes entre si, os quais classificaram os lotes 1 e 2 como de maior vigor em comparação aos demais lotes. No teste de condutividade elétrica massal, os lotes 1,3 e 5 foram classificados como de maior vigor, devido a menor lixiviação de eletrólitos. De maneira diferente do que foi observado nos testes de primeira contagem de germinação, de frio e de emergência de plântulas, o lote 2 nesse teste foi classificado como o de menor nível de vigor, juntamente com o lote 4.

A maioria dos testes destacou os lotes 3 e 5 , para a cultivar IRGA 424, e o lote 1, para a cultivar Puitá Inta CL, como sendo os de maior potencial fisiológico.
De acordo com esses resultados, os testes de germinação e de vigor apresentaram informações similares sobre o potencial fisiológico, principalmente para os lotes de qualidade superior. Com relação à identificação dos lotes de sementes de vigor intermediário, para as duas cultivares, a mesma ainda representa um desafio para as pesquisas em sementes, uma vez que dependendo do teste realizado, é maior e/ou menor que o vigor real dos lotes. Esta é uma observação comum entre pesquisadores, especialmente quando os lotes de sementes possuem diferenças estreitas de qualidade (Miguel e Marcos -Filho, 2002).

Os dados do teste de lixiviação de potássio, envolvendo as combinações volume de água/períodos de avaliação, encontram-se nas Tabelas 2 e 3 , nas quais constatou-se que as diferentes combinações estratificaram os lotes, para ambas as cultivares, em função do vigor das sementes. Analisando os resultados, verificou-se que a combinação de 50 sementes $/ 20$ $\mathrm{mL}$ (Tabela 2), possibilitou classificar os lotes, em todos os períodos de avaliação, para as duas cultivares.

Para a cultivar IRGA 424, o lote 5 apresentou-se como de maior vigor, os lotes 1,2 e 4 como aqueles de menor vigor e o lote 3 como intermediário, na maioria dos períodos de avaliação (Tabela 2). De forma geral, os resultados de lixiviação de potássio, realizado com 50 sementes imersas em $20 \mathrm{~mL}$ de água, foram semelhantes aos observados nos testes de emergência de plântulas em campo e condutividade elétrica massal (Tabela 1), quanto à indicação dos lotes de maior e menor nível de vigor. 
Com relação aos lotes da cultivar Puitá Inta CL, para as combinações 50 sementes $/ 20 \mathrm{~mL}$ (Tabela 2), o teste de lixiviação de potássio não apresentou concordância com os testes de germinação, primeira contagem de germinação, teste de frio e emergência de plântulas em campo (Tabela 1), ou seja, enquanto estes testes definiram como de maior qualidade fisiológica os lotes 1 e 2, o teste de lixiviação de potássio, classificou como de maior vigor os lotes 1,3 e 5, e como de menor qualidade o lote 2 .

Com relação à combinação 50 sementes $/ 50 \mathrm{~mL}$ de água destilada, nos diferentes períodos de avaliação, para as duas cultivares (Tabela 3), verificou-se uma estratificação mais clara dos lotes, assemelhando-se os resultados deste, com os resultados dos testes de caracterização inicial.

Tabela 2. Valores médios ( $\mu \mathrm{g} \mathrm{K} \mathrm{g}^{-1}$ semente) da lixiviação de potássio, na combinação 50 sementes/ $20 \mathrm{~mL}$ dos dez lotes de sementes, das duas cultivares de arroz, em cada período de imersão.

\begin{tabular}{cccccccc}
\hline Cultivar & Lote & \multicolumn{7}{c}{ Período de avaliação (minutos) } \\
\hline & & 30 & 60 & 90 & 120 & 150 & 180 \\
\hline \multirow{3}{*}{ Irga 424 } & 1 & $163,0 \mathrm{c}$ & $211,2 \mathrm{c}$ & $215,5 \mathrm{c}$ & $326,0 \mathrm{~b}$ & $539,0 \mathrm{c}$ & $587,0 \mathrm{c}$ \\
& 2 & $203,5 \mathrm{~d}$ & $214,0 \mathrm{c}$ & $215,5 \mathrm{c}$ & $437,0 \mathrm{c}$ & $510,0 \mathrm{c}$ & $635,0 \mathrm{~d}$ \\
& 3 & $121,5 \mathrm{~b}$ & $174,0 \mathrm{~b}$ & $191,5 \mathrm{~b}$ & $295,0 \mathrm{~b}$ & $433,0 \mathrm{~b}$ & $450,0 \mathrm{~b}$ \\
& 4 & $154,0 \mathrm{c}$ & $108,7 \mathrm{c}$ & $218,0 \mathrm{c}$ & $394,0 \mathrm{c}$ & $506,0 \mathrm{c}$ & $561,0 \mathrm{c}$ \\
& 5 & $90,0 \mathrm{a}$ & $112,5 \mathrm{a}$ & $112,5 \mathrm{a}$ & $206,0 \mathrm{a}$ & $243,0 \mathrm{a}$ & $239,0 \mathrm{a}$ \\
\hline CV (\%) & & 8,54 & 12,04 & 7,51 & 14,02 & 13,96 & 10,80 \\
\hline \multirow{2}{*}{ Puitá Inta CL } & 1 & $118,5 \mathrm{a}$ & $175,2 \mathrm{a}$ & $154,2 \mathrm{a}$ & $285,0 \mathrm{a}$ & $353,0 \mathrm{a}$ & $375,0 \mathrm{a}$ \\
& 2 & $148,7 \mathrm{~b}$ & $195,5 \mathrm{~b}$ & $193,2 \mathrm{~b}$ & $442,0 \mathrm{c}$ & $490,0 \mathrm{~b}$ & $504,0 \mathrm{c}$ \\
& 3 & $130,7 \mathrm{a}$ & $168,5 \mathrm{a}$ & $159,2 \mathrm{a}$ & $301,0 \mathrm{a}$ & $349,0 \mathrm{a}$ & $379,0 \mathrm{a}$ \\
& 4 & $162,7 \mathrm{c}$ & $191,0 \mathrm{~b}$ & $195,0 \mathrm{~b}$ & $411,0 \mathrm{c}$ & $421,0 \mathrm{~b}$ & $435,0 \mathrm{~b}$ \\
& 5 & $121,7 \mathrm{a}$ & $161,5 \mathrm{a}$ & $167,2 \mathrm{a}$ & $339,0 \mathrm{~b}$ & $366,0 \mathrm{a}$ & $336,0 \mathrm{a}$ \\
\hline
\end{tabular}

*Médias seguidas pela mesma letra na coluna não diferem entre si, pelo teste de Scott-Knott, $(p>0,05)$.

Tabela 3. Valores médios ( $\mu \mathrm{g} \mathrm{K} \mathrm{g}^{-1}$ semente) da lixiviação de potássio na combinação 50 sementes/ $50 \mathrm{~mL}$ dos dez lotes de sementes, das duas cultivares de arroz, em cada período de avaliação.

\begin{tabular}{|c|c|c|c|c|c|c|c|}
\hline \multirow[t]{2}{*}{ Cultivar } & \multirow[t]{2}{*}{ Lote } & \multicolumn{6}{|c|}{ Período de avaliação (minutos) } \\
\hline & & 30 & 60 & 90 & 120 & 150 & 180 \\
\hline \multirow{5}{*}{ Irga 424} & 1 & $104,0 \mathrm{c}$ & $120,2 \mathrm{c}$ & $153,0 \mathrm{c}$ & $177,7 \mathrm{~b}$ & $160,0 \mathrm{~b}$ & $211,2 b$ \\
\hline & 2 & $138,0 \mathrm{~d}$ & $141,2 \mathrm{c}$ & $186,0 \mathrm{~d}$ & $220,2 \mathrm{~b}$ & $209,2 \mathrm{~b}$ & $247,0 \mathrm{~b}$ \\
\hline & 3 & $65,0 \mathrm{~b}$ & $52,0 \mathrm{a}$ & $102,0 \mathrm{~b}$ & $136,7 \mathrm{a}$ & $101,0 \mathrm{a}$ & $139,0 \mathrm{a}$ \\
\hline & 4 & $110,0 \mathrm{c}$ & $88,75 \mathrm{~b}$ & $152,2 \mathrm{c}$ & $179,0 \mathrm{~b}$ & $209,2 \mathrm{~b}$ & $173,0 \mathrm{a}$ \\
\hline & 5 & $46,0 \mathrm{a}$ & $42,75 \mathrm{a}$ & $71,2 \mathrm{a}$ & 86,7 a & $73,2 \mathrm{a}$ & $119,7 \mathrm{a}$ \\
\hline \multicolumn{2}{|l|}{ CV $(\%)$} & 8,54 & 12,04 & 7,51 & 14,02 & 13,96 & 10,8 \\
\hline \multirow{5}{*}{ Puitá Inta CL } & 1 & $61,2 \mathrm{a}$ & $69,2 \mathrm{a}$ & $101,0 \mathrm{a}$ & $118,7 \mathrm{a}$ & $145,2 \mathrm{a}$ & $161,0 \mathrm{a}$ \\
\hline & 2 & $107,0 \mathrm{c}$ & $89,2 \mathrm{~b}$ & $136,2 \mathrm{~b}$ & $162,7 \mathrm{a}$ & $149,7 \mathrm{a}$ & $185,7 \mathrm{a}$ \\
\hline & 3 & $84,0 \mathrm{~b}$ & $96,0 \mathrm{~b}$ & $129,0 \mathrm{~b}$ & $133,7 \mathrm{a}$ & $136,7 \mathrm{a}$ & $141,7 \mathrm{a}$ \\
\hline & 4 & $103,2 \mathrm{c}$ & $104,7 \mathrm{~b}$ & $117,2 \mathrm{~b}$ & $149,7 \mathrm{a}$ & $157,2 \mathrm{a}$ & $160,0 \mathrm{a}$ \\
\hline & 5 & $75,0 \mathrm{~b}$ & 89,2 b & $100,7 \mathrm{a}$ & $119,2 \mathrm{a}$ & $138,2 \mathrm{a}$ & $136,7 \mathrm{a}$ \\
\hline CV (\%) & & 7,15 & 7,65 & 7,96 & 9,93 & 6,62 & 11,22 \\
\hline
\end{tabular}

*Médias seguidas pela mesma letra na coluna não diferem entre si, pelo teste de Scott-Knott, $(\mathrm{p}>0,05)$. 
Para a cultivar IRGA 424 (Tabela 3), os períodos de avaliação de 60, 120 e 150 minutos, classificaram os lotes 3 e 5 como de maior vigor e os demais como de menor vigor, concordando com os resultados de emergência de plântulas em campo e condutividade elétrica massal. Além disto, o teste de lixiviação de potássio permitiu avaliar a qualidade de sementes de forma semelhante aos demais testes em um menor período de tempo (60 minutos de imersão).

No teste de lixiviação de potássio foi possível destacar, para a cultivar IRGA 424, o comportamento inferior dos lotes 1,2 e 4, quando comparados aos lotes 3 e 5 (Tabela 3). Estes resultados foram semelhantes aos obtidos nos demais testes de vigor, já aos 60 minutos de imersão e no volume de água de $50 \mathrm{~mL}$ (Tabela 1).

Este teste permite a avaliação do vigor das sementes em menor tempo, sendo que o início da imersão é acompanhado pela rápida lixiviação de exsudados, principalmente o íon potássio, que é o cátion que está em maior concentração nas membranas e mais disponível nas células vegetais (Taiz e Zeiger, 2009).

Para a cultivar Puitá Inta CL (Tabela 3), a combinação 50 sementes $/ 50 \mathrm{~mL}$ estratificou os lotes em diferentes níveis de vigor até os 90 minutos de avaliação, a partir desse período não houve diferença significativa entre os lotes. Nos períodos de avaliação de 30 e 60 minutos, houve a classificação do lote 1 como de qualidade fisiológica superior aos demais, resultado este semelhante ao do teste de germinação, que obtive a mesma classificação. No entanto, para o período de 90 minutos, os lotes 1 e 5 foram considerados como de maior vigor, concordando com os resultados do teste de condutividade elétrica massal.

$\mathrm{O}$ teste de condutividade elétrica, que tem base no mesmo princípio, fornece resultados apenas depois de um período de imersão de 24 horas, quando realizado de acordo com o procedimento atual (AOSA, 1983). Woodstock et al. (1985) relataram que a avaliação de potássio e cálcio, liberados durante imersão das sementes, foi melhor para a avaliação do vigor do que o total de eletrólitos avaliado pelo teste de condutividade elétrica.

A análise de correlação mostrou a existência de relacionamento significativo e negativo entre a combinação de 50 sementes em $50 \mathrm{~mL}$, imersas por 60 minutos, no teste de lixiviação de potássio com a emergência em campo para a cultivar IRGA 424 (Tabela 4). Para a cultivar Puitá Inta CL, os valores da lixiviação de potássio, quando realizado nestas condições, correlacionaramse negativa e significativamente com os testes de germinação e primeira contagem de germinação. A partir destas observações admite-se que, ao usar sementes de um mesmo lote homogêneo, ocorrerão variações proporcionais e com sentidos opostos, nos referidos testes, visto que as correlações foram negativas, as quais acredita-se que se devam a qualidade das sementes.

Tabela 4. Coeficientes de correlação simples (r) entre os dados obtidos pelo teste de lixiviação de potássio com 50 sementes imersas em $50 \mathrm{~mL}$ de água deionizada, durante 60 minutos e os demais testes: germinação (G), primeira contagem (PC), frio (F), emergência (EM) e condutividade elétrica massal (CEM), para as duas cultivares.

\begin{tabular}{ccccccc}
\hline Cultivares & Lixiviação de $\mathrm{K}$ & $\mathrm{G}$ & $\mathrm{PC}$ & $\mathrm{F}$ & $\mathrm{EM}$ & CEM \\
\hline Irga 424 & $50 \mathrm{sem} / 50 \mathrm{~mL} / 60^{\circ}$ & $-0,82$ & $-0,75$ & $-0,83$ & $-0,90^{*}$ & $0,95^{*}$ \\
Puitá Inta CL & $50 \mathrm{sem} / 50 \mathrm{~mL} / 60^{\circ}$ & $-0,92^{*}$ & $-0,90^{*}$ & $-0,67$ & $-0,74$ & $-0,76$ \\
\hline
\end{tabular}

* Significativos a 5\%, pelo teste de $\mathrm{F}$.

Desse modo, se o teste de lixiviação de potássio foi capaz de indicar as variações na emergência das plântulas, poder-se-ia classificá-lo como eficiente para separar lotes de sementes de arroz em função do vigor, tal como foi apontado em outras culturas por diversos autores (Ávila et al., 2005; Kikuti et al., 2008; Alves e Sá, 2010).
Na Tabela 5, estão apresentados os valores médios dos resultados do teste de germinação, primeira contagem de germinação e emergência em campo que foram comparados ao teste de lixiviação de potássio (50 sementes $/ 50 \mathrm{~mL} / 60$ minutos) para confirmar a eficiência deste em classificar os lotes em diferentes níveis de vigor. 
Tabela 5. Valores médios da germinação (G), primeira contagem de germinação (PC), emergência em campo (EM) e lixiviação de potássio (LK), dos lotes de arroz.

\begin{tabular}{ccccc}
\hline Lote & $\mathrm{G}(\%)$ & PC $(\%)$ & EM $(\%)$ & $\mathrm{LK}\left(\mu \mathrm{g} \mathrm{K}^{+} \mathrm{g}^{-1}\right)$ \\
\hline 1 & $92 \mathrm{a}$ & $90 \mathrm{a}$ & $89 \mathrm{a}$ & $37,89 \mathrm{a}$ \\
2 & $96 \mathrm{a}$ & $91 \mathrm{a}$ & $92 \mathrm{a}$ & $35,21 \mathrm{a}$ \\
3 & $90 \mathrm{a}$ & $85 \mathrm{a}$ & $83 \mathrm{~b}$ & $40,17 \mathrm{a}$ \\
4 & $96 \mathrm{a}$ & $94 \mathrm{a}$ & $95 \mathrm{a}$ & $38,74 \mathrm{a}$ \\
5 & $95 \mathrm{a}$ & $90 \mathrm{a}$ & $89 \mathrm{a}$ & $41,20 \mathrm{a}$ \\
6 & $95 \mathrm{a}$ & $94 \mathrm{a}$ & $83 \mathrm{~b}$ & $69,50 \mathrm{~b}$ \\
7 & $94 \mathrm{a}$ & $92 \mathrm{a}$ & $84 \mathrm{~b}$ & $86,38 \mathrm{c}$ \\
8 & $92 \mathrm{a}$ & $72 \mathrm{~b}$ & $77 \mathrm{c}$ & $111,36 \mathrm{~d}$ \\
9 & $87 \mathrm{a}$ & $78 \mathrm{~b}$ & $87 \mathrm{a}$ & $65,15 \mathrm{~b}$ \\
10 & $94 \mathrm{a}$ & $93 \mathrm{a}$ & $89 \mathrm{a}$ & $35,57 \mathrm{a}$ \\
11 & $93 \mathrm{a}$ & $90 \mathrm{a}$ & $85 \mathrm{~b}$ & $32,38 \mathrm{a}$ \\
12 & $91 \mathrm{a}$ & $86 \mathrm{a}$ & $84 \mathrm{~b}$ & $80,02 \mathrm{c}$ \\
\hline $\mathrm{CV}(\%)$ & 3,88 & 5,10 & 4,23 & 9,06 \\
\hline
\end{tabular}

*Médias seguidas pela mesma letra na coluna não diferem entre si, pelo teste de Scott- Knott, $(\mathrm{p}>0,05)$.

$\mathrm{Na}$ análise da germinação das sementes, não foi observada diferença estatística significativa entre os lotes. Isso porque as condições ideais da realização do teste de germinação nem sempre permitem observar as pequenas diferenças no potencial de qualidade dos lotes (Delouche e Baskin, 1973). Assim, diferenças no comportamento de lotes com germinação semelhante estão associadas ao fato de que os primeiros sinais da deterioração ocorrem antes da perda da viabilidade. Os resultados da primeira contagem de germinação classificaram os lotes em dois níveis de vigor, sendo os lotes 8 e 9 os de menor vigor em relação aos demais.

A emergência das plântulas separou os lotes em três níveis, destacando os lotes 1, 2, 4, 5, 9 e 10 como de maior vigor, o lote 8 como de menor potencial e os demais como intermediários. O teste de lixiviação de potássio destacou os lotes $1,2,3,4,5,10$ e 11 como de maior potencial e o lote 8 como o de menor vigor, concordando com os resultados dos outros testes, porém observa-se variações de classificação em lotes de potencial fisiológico intermediário. Esses resultados são coerentes, pois de acordo com MarcosFilho (2005), é esperado que os testes de vigor permitam distinguir com segurança os lotes de alto dos de baixo vigor e que as diferenças detectadas estejam relacionadas às características da semente e ao comportamento das sementes no armazenamento e no campo.
Os testes de vigor, além de ranquear os lotes, devem associar-se ao desempenho das plântulas em campo, a fim de um monitoramento da eficiência dos procedimentos adotados em laboratório (Marcos-Filho, 1999), o que foi conseguido neste trabalho, comprovando, nessas condições, ser um teste bastante promissor na separação de diferentes níveis de vigor em sementes de arroz.

\section{Conclusões}

O teste de lixiviação de potássio é eficiente para avaliar o vigor de sementes de arroz. A combinação de 50 sementes puras imersas em $50 \mathrm{~mL}$ de água destilada e deionizada, a $25^{\circ} \mathrm{C}$ durante 60 minutos, representa o procedimento mais eficiente para classificar lotes de sementes de arroz, em função de sua qualidade fisiológica.

\section{Referências}

ABDUL-BAKI, A.A.; BAKER, J.E. Are changes in cellular organelles or membranes related to vigor loss in seeds. Seed Science and Technology, v.1, p.89-125, 1973.

ALVES, C.Z.; SÁ, M.E.; Avaliação do vigor de sementes de rúcula pelo teste de lixiviação de potássio. Revista Brasileira de Sementes, v.32, n.2 p.108-116, 2010. http://www.scielo.br/scielo.php?pid=S010131222010000200013\&script=sci_arttext 
ALVES, E.; CAVARIANI, C.; CORRÊA, M.R.; SOUZA, F.L.G.; CORRÊA, T.M.; NAKAGAWA, J. Efeito dos períodos de envelhecimento na lixiviação de íons e proteínas solúveis em sementes de milho. Revista Brasileira de Sementes, v.26, n.2, p. 119125, 2004. http://www.scielo.br/scielo.php?script=sci_arttext\&pid $=$ S0101-31222004000200017

ASSOCIATION OF OFFICIAL SEED ANALYSTS. Seed vigour testing handbook. East Lansing: AOSA, 1983. 93p. (Contribution, 32).

AVILA, M.R.; BRACCINI, A.L.; SCAPIM, C.A.; MARTORELLI, D.T.; ALBRECHT, L.P. Testes de laboratório em sementes de canola e a correlação com a emergência das plântulas em campo. Revista Brasileira de Sementes, v.27, n.1, p.62-70, 2005. http://www.scielo.br/scielo. php?script=sci_arttext\&pid=S0101-31222005000100008

BRASIL. Ministério da Agricultura, Pecuária e Abastecimento. Regras para análise de sementes. Ministério da Agricultura, Pecuária e Abastecimento. Secretaria de Defesa Agropecuária. Brasília, DF: Mapa/ACS, 2009. 395p. http://www.agricultura.gov.br/images/MAPA/ arquivos_portal/ACS/sementes_web.pdf

DELOUCHE, J.C.; BASKIN, C.C. Accelerated aging techniques for predicting the relative storability of seed lots. Seed Science and Technology, v.1, n.2, p.427-52, 1973.

DIAS, D.C.F.S.; MARCOS-FILHO, J. Testes de vigor baseados na permeabilidade das membranas celulares: condutividade elétrica. Informativo ABRATES, v.5, n.1, p.26-36, 1995.

DIAS, D.C.F.S.; MARCOS-FILHO, J.; CARMELLO, Q.A.C. Potassium leakage test for the evaluation of vigour in soybean seeds. Seed Science and Technology, v.24, p.7-18, 1997.

FERREIRA, D.F. SISVAR: um programa para análises e ensino de estatística. Revista Symposium, v.6, p.36-41, 2008. http://www.fadminas.org.br/ symposium/12_edicoes/artigo_5.pdf

FESSEL, S.A.; PANOBIANCO, M.; SOUZA, C.R.; VIEIRA, R.D. Teste de condutividade elétrica em sementes de soja armazenadas sob diferentes temperaturas. Bragantia, v.69, n.1, p.207-214, 2010. http://www.scielo. br/scielo.php?pid=S0006-87052010000100026\&script=sci_arttext

INTERNATIONAL SEED TESTING ASSOCIATION - ISTA. Handbook of vigor test methods. 3.ed. Zurich, 1995. 117p.
KIKUTI, H.; MEDINA, P.F.; KIKUTI, A.L.P.; RAMOS, N.P. Teste de lixiviação de potássio para avaliação do vigor de sementes de amendoim. Revista Brasileira de Sementes, v.30, n.1, p.10-18, 2008. http://www.scielo.br/scielo.php?pid=S0101$31222008000100002 \&$ script $=$ sci_arttext

MARCOS-FILHO, J. Fisiologia de sementes de plantas cultivadas. Piracicaba: FEALQ, 2005. 495p.

MARCOS-FILHO, J. Testes de vigor: importância e utilização. In: KRZYZANOWSKI, F.C.; VIEIRA, R.D.; FRANÇA-NETO, J.B. (Ed.). Vigor de sementes: conceitos e testes. Londrina: ABRATES, 1999. p.1-21.

MATTHEWS, S.; POWELL, A.A. Electrical conductivity vigour test: physiological basic and use. ISTA News Bulletin, Zurich, n.131, p.32-35, Apr. 2006. https://www.seedtest.org/upload/cms/user/STI131April2006.pdf

MIGUEL, M.V.C.; MARCOS-FILHO, J. Potassium leakage and maize seed physiological potential. Scientia Agricola, v.59, n.2, p.315-319, 2002. http://www.scielo.br/scielo.php?pid=S010390162002000200017\&script=sci_arttext

TAIZ, L.; ZEIGER, E. Fisiologia Vegetal. 4.ed. Porto Alegre: Artmed, 2009. 819p.

VANZOLINI, S.; NAKAGAWA, J. Lixiviação de potássio na avaliação da qualidade fisiológica de sementes de amendoim. Revista Brasileira de Sementes, v.25, n.2, p.7-12, 2003. http://www.scielo.br/scielo. php?pid=S0101-31222003000400002\&script=sci_arttext

VIEIRA, R.D. Teste de condutividade elétrica. In: VIEIRA, R.D.; CARVALHO, N.M. (Ed.) Testes de vigor em sementes. Jaboticabal: FUNEP, 1994. p.103-132.

VIEIRA, R.D.; TEKRONY, D.M.; EGLI, D.B.; BRUENNING, W.P.; PANOBIANCO, M. Temperature during soybean seed storage and the amount of electrolytes of soaked seeds solution. Scientia Agricola, v.65, n.5, p.496-501, 2008. http://www.scielo.br/scielo.php?pid=S0103$90162008000500008 \&$ script=sci_arttext

WOODSTOCK, L.W.; FURMAN, K.; LEFFLER, H.R. Relationship between weathering deterioration and germination, respiratory metabolism and mineral leaching from cotton seeds. Crop Science, v.25, p. $459-466,1985$. 